\title{
Characterization of the nighttime low-latitude water ice deposits in the NASA Ames Mars General Circulation Model 2.1 under present-day atmospheric conditions
}

\author{
Steven M. Nelli, ${ }^{1}$ James R. Murphy, ${ }^{2}$ William C. Feldman, ${ }^{3}$ \\ and James R. Schaeffer ${ }^{4}$ \\ Received 29 October 2008; revised 9 July 2009; accepted 23 July 2009; published 5 November 2009.
}

[1] This effort advances the exploration of the current Martian water cycle by analyzing the nighttime equatorial water ice deposits in the NASA Ames Mars General Circulation Model (version 2.1). The possibility that the current Martian water cycle plays a role in the generation or maintenance of the longitudinally confined tropical maxima of water-equivalent hydrogen (WEH) in the near-surface regolith is also investigated. Mars Odyssey Orbiter Gamma Ray suite observations indicate that tropical latitudes exhibit longitudinally distinct maxima of the presence of near-surface hydrogen, likely in the form of hydrated minerals, in the Arabia and Tharsis regions. Atmospheric numerical simulations with the NASA Ames Mars General Circulation Model produce an annual water cycle that faithfully reproduces the cycle derived from Mars Global Surveyor Thermal Emission Spectrometer measurements. This simulated water cycle produces maxima of near-surface tropical water condensation at longitudes consistent with the WEH maxima regions, though these maxima are shifted north of the Odyssey Gamma Ray suite WEH regions. While the simulated pattern of near-surface tropical water condensation does exhibit a longitudinal structure consistent with the observed WEH maxima, it is concluded that the current water cycle is not playing a dominant role in the formation or retention of those maxima. Thus, atmospheric involvement in the formation of the WEH-rich regions must occur during past climatic conditions, if at all.

Citation: Nelli, S. M., J. R. Murphy, W. C. Feldman, and J. R. Schaeffer (2009), Characterization of the nighttime low-latitude water ice deposits in the NASA Ames Mars General Circulation Model 2.1 under present-day atmospheric conditions, J. Geophys. Res., 114, E11003, doi:10.1029/2008JE003289.

\section{Introduction}

[2] Previous modeling [Hinson and Wilson, 2004; Feldman et al., 2005; Basilevsky et al., 2006] has produced water ice deposits upon the surface of Mars in the tropics under present-day atmospheric conditions. Deposits occur along longitudinal corridors similar in location to that of the equatorial water-equivalent hydrogen (WEH) regions identified by the Mars Odyssey Gamma Ray Spectrometer suite of instruments, GRS/NS (Figure 1) [Feldman et al., 2002, 2005; Boynton et al., 2002; Mitrofanov et al., 2002]. Both Feldman et al. [2005] and Basilevsky et al. [2006] suggest that these water ice deposits onto, and/or water vapor diffusion into, the regolith may be adsorbed or chemically bound to hydrating minerals that are stable at local surface/ subsurface conditions [Feldman et al., 2004b; Fialips et al.,

\footnotetext{
${ }^{1}$ Department of Atmospheric, Oceanic, and Space Sciences, University of Michigan, Ann Arbor, Michigan, USA.

${ }^{2}$ Department of Astronomy, New Mexico State University, Las Cruces, New Mexico, USA.

${ }^{3}$ Planetary Science Institute, Tucson, Arizona, USA.

${ }^{4}$ NASA Ames Research Center, Moffett Field, California, USA.

Copyright 2009 by the American Geophysical Union. 0148-0227/09/2008JE003289
}

2005]. While these models show little surface water ice formation along the WEH desiccated lanes of $-45^{\circ} \mathrm{E}$ and $+90^{\circ} \mathrm{E}$, the overall correlation of simulated integrated surface water ice deposition with WEH maxima in these models is good for Arabia and less favorable for Medusae Fossae. The current distribution of the water ice deposits in these models also contains a northern hemisphere bias. So, not only is the water ice deposition important for the formation of these observed WEH regions, but there also needs to be a specific heterogeneous distribution of hydrating minerals to make up for deficiencies in the water ice distribution pattern. However, note that the WEH distribution probably responds to the long-term average precipitation of water ice, which may have switched dominant hemispheres about 25,000 years ago when the precession of the spin axis had perihelion at the summer solstice in the north rather than in the south [Montmessin et al., 2007]. These prior papers [Hinson and Wilson, 2004; Feldman et al., 2005; Basilevsky et al., 2006], while mentioning the tropical ice formation phenomenon, lacked depth in describing this process. This paper continues the study of the current Martian water cycle by characterizing the formation of equatorial water ice (where, when, how, etc.) in the NASA Ames Mars General Circulation Model Version 2.1 


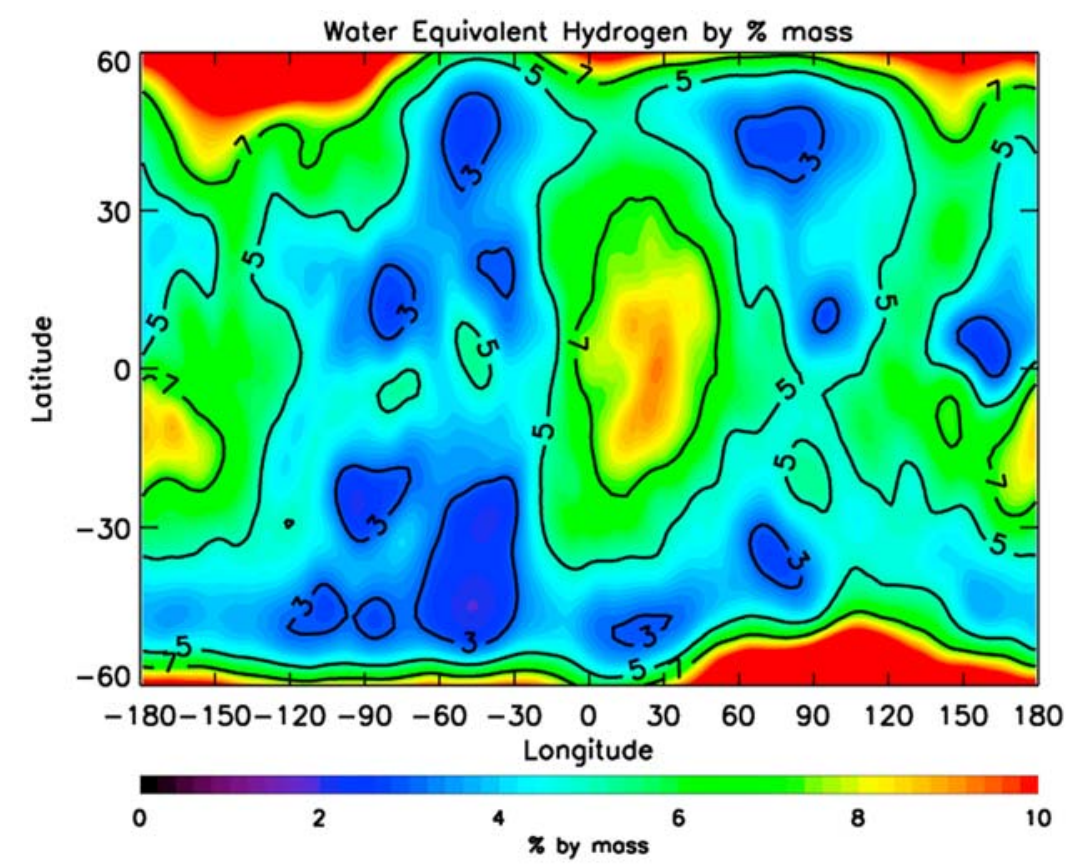

Figure 1. This map shows the surprising abundance of WEH in the equatorial regions between $\pm 60^{\circ}$ latitude. The origin of this WEH is disputed since near-surface water ice is unstable [Mellon and Jakosky, 1993]. The black contours represent 3\%,5\%, and 7\% by mass WEH. Data is from Feldman et al. [2004a].

(GCMv2.1) and looks once again at whether or not the current tropical water ice deposition can form/maintain the equatorial WEH-rich regions.

\subsection{Observed Water Cycle}

[3] The main source for the atmospheric water vapor at current times is the sublimation of the north polar residual cap [Jakosky and Haberle, 1992]. Maximum water vapor abundance occurs at midsummer over the north pole [Smith, 2002, 2004] due to increased temperatures raising the sublimation rate of the perpetual water ice cap. A maximum of $\sim 60 \mathrm{pr} \mu \mathrm{m}$ (precipitable microns) arises during northern summer; while $\sim 30$ pr $\mu \mathrm{m}$ arises in southern summer [Smith, 2002]. The reduced maximum in the southern hemisphere is due to the $\mathrm{CO}_{2}$ veneer [Byrne and Ingersoll, 2003; Bibring et al., 2005] of the south polar cap remaining throughout the year, not allowing the underlying ice to sublimate [Jakosky and Haberle, 1992]. The removal of such a veneer is predicted to create atmospheric abundances greater than $100 \mathrm{pr} \mu \mathrm{m}$ over the south polar cap due to the general higher insolation rate during this season compared to northern summer [Davies et al., 1977]. In both hemispheres, minimum water vapor abundance occurs in late fall/winter with amounts $<5 \mathrm{pr} \mu \mathrm{m}$ [Smith, 2002, 2004]. The temperatures of the polar night cause most of the water vapor to freeze out of the atmosphere and be deposited on the surface, starting first at the highest latitudes and progressing toward lower latitudes as winter approaches. It has recently come to light that the Thermal Emission Spectrometer (TES) on Mars Global Surveyor (MGS) values for water vapor abundance may be too high by a factor of $\sim 1.5$ [Fouchet et al., 2007; M. Smith, private communication, 2007]. The absolute values for the atmospheric water vapor column abundance quoted in this paper are the newly adjusted values and not those from the original Smith [2002, 2004, 2006] publications. The qualitative results are not affected, as the error was systematic across the data set. However, since the corrected TES values have not yet been published, the original Smith [2002, 2004, 2006] references will continue to be used throughout this paper when referring to the atmospheric water vapor column abundance.

[4] Water ice clouds form in the tropics during aphelion $\left(\mathrm{L}_{\mathrm{s}} \sim 70^{\circ}\right)$ and over the seasonal ice caps. The tropical clouds during aphelion are low-altitude clouds, $\sim 10 \mathrm{~km}$, and are located at the ascending branch $\left(0^{\circ} \mathrm{N}-30^{\circ} \mathrm{N}\right)$ of the Hadley cell. At latitudes $>10^{\circ} \mathrm{N}$ during northern hemisphere summer, the Hadley cell flow turns southward at altitudes greater than $10 \mathrm{~km}$ [Clancy et al., 1996]. Water vapor abundance above $10 \mathrm{~km}$ may be strongly depleted by formation and gravitational settling of water ice particles. Thus, when low-altitude saturation prevails, the water transport southward can be diminished. During perihelion $\left(\mathrm{L}_{\mathrm{s}} \sim 250^{\circ}\right)$, low-altitude clouds do not form. This is due to the atmospheric conditions being warmer and drier. The warmer conditions occur because of higher solar fluxes and dust opacities; this raises the altitude for water vapor saturation [Clancy et al., 1996]. The drier conditions occur because of the lack of an exposed water ice cap in the south [Jakosky and Haberle, 1992]. The warmer, drier conditions rarely allow for cloud formation at the ascending branch of the perihelion Hadley cell [Smith et al., 2001a].

\subsection{Water-Equivalent Hydrogen}

[5] The Mars Odyssey orbiter is carrying a suite of instruments, collectively known as the Gamma Ray Spec- 
trometer (GRS) [Boynton et al., 2004]. The Neutron Spectrometer (NS) and the High-Energy Neutron Detector (HEND) aboard GRS can indirectly sample hydrogen in the upper meter of the surface [Feldman et al., 2002; Boynton et al., 2002; Mitrofanov et al., 2002; Boynton et al., 2004]. Since $99.985 \%$ of all hydrogen is in the form of ${ }^{1} \mathrm{H}$ (no neutrons), hydrogen is detected by its large rate of energy-loss collisions of neutrons, after production by cosmic rays. Water content in the upper meter of Martian soil is derived from this measurement of the abundance of hydrogen. While near-surface hydrogen can exist in many compounds, including $\mathrm{H}_{2} \mathrm{O}_{2}$, methane, and $\mathrm{OH}$, it is most apt to be in the form of $\mathrm{H}_{2} \mathrm{O}$ [Feldman et al., 2002; Boynton et al., 2002; Mitrofanov et al., 2002]. Thus, abundance results are given in terms of "water-equivalent hydrogen," which assumes that all detectable hydrogen is locked up in water molecules [Feldman et al., 2004a].

[6] Current analysis of thermal, epithermal and fast neutrons measured by the NS reveal water-rich soil poleward of $\sim 55^{\circ} \mathrm{N}$ and $60^{\circ} \mathrm{S}$ latitude. This water-rich soil is calculated to range up to $\sim 100 \% \mathrm{WEH}$ by mass at high northern latitudes and between 20 and $50 \%$ by mass WEH at high southern latitudes [Feldman et al., 2004a]. These polar regions of ice-rich soil are in close agreement with theoretical calculations [Farmer and Doms, 1979; Mellon and Jakosky, 1993; Schorghofer and Aharonson, 2005] on the stability of ground ice on Mars. There are also two equatorial regions (Figure 1) with significant near-surface mass fractions of WEH (up to $10 \%$ ), located in Arabia $\left(25^{\circ} \mathrm{E}\right.$ and $\left.5^{\circ} \mathrm{S}\right)$ and the Medusae Fossae $\left(180^{\circ} \mathrm{E}\right.$ and $\left.15^{\circ} \mathrm{S}\right)$ region of the Tharsis bulge [Feldman et al., 2004a]. These regions are probably subsurface deposits of chemically and/ or physically bound $\mathrm{H}_{2} \mathrm{O}$ since water ice is predicted to be thermodynamically unstable in the equatorial region [Leighton and Murray, 1966; Farmer and Doms, 1979; Mellon and Jakosky, 1993; Feldman et al., 2004a]. Regardless of what state (ice or hydrate) the water is in at $10 \%$ by mass, if you muse that one shovel full of regolith is roughly $5 \mathrm{~kg}$, a half kilogram of the mass within that shovel is water (equivalent to two cups of water). At these amounts, it is believable to think that extraction of this water might be capable of sustaining long-term human exploration upon the surface.

[7] The locations of the equatorial WEH-rich regions are inconsistent with any correlation to composition, topography, present-day atmospheric water abundance, latitude, or thermophysical properties [Jakosky et al., 2005]. Jakosky et al. [2005] calculated the degree of correlation between the epithermal neutrons (used to obtain WEH abundance) and the various relevant physical parameters (composition, topography, present-day atmospheric water abundance, latitude, or thermophysical properties). The correlation coefficient for each parameter is less than 0.3 , resulting in a very weak correlation if any. The strongest correlations are between neutron abundance and the peak atmospheric water abundance, the mean annual subsurface temperature, and latitude. However, none of these parameters allude to a persuasive link between the observed physical properties and the near-surface water abundance. One objective of this paper involves testing whether surface water ice deposition patterns are better correlated with, and can account for, the observed WEH-rich regions.

\subsection{Advancing Our Understanding of Nighttime Atmospheric Phenomena}

[8] This paper focuses upon better characterizing the nighttime water ice deposition process briefly mentioned in papers by Hinson and Wilson [2004], Feldman et al. [2005], and Basilevsky et al. [2006] using the Ames GCMv2.1. Feldman et al. [2005] and Basilevsky et al. [2006], in particular, focus on this water ice deposition being a source of hydration for certain minerals that would, in turn, produce the equatorial WEH-rich regions. We add to this discussion at the end of the paper. We focus primarily on analyzing the annual simulated precipitation on Mars: Where, when, and how does this precipitation occur? The Ames GCMv2.1 permits the study of many nighttime atmospheric conditions (i.e., cloud opacity, temperatures, atmospheric water vapor abundances, etc.) on Mars that cannot be observed by most orbiting instruments because of the instrument's reliance on surface temperatures $>220 \mathrm{~K}$ and sunlight [Smith et al., 2001b, 2009]. Section 2 encompasses a description of the version of the Ames GCMv2.1 used in this study. Section 3 validates the simulated water cycle with observation. Section 4 presents the results of our work while section 5 is a discussion of the implications our work might have on the current equatorial WEH-rich regions.

\section{Model Description}

[9] The NASA Ames Mars GCMv2.1 is a finite difference numerical grid point model for Mars' atmosphere [Haberle et al., 1993, 1999]. Current model geophysical processes include (1) the treatment of a two-stream solution to the radiative transfer equation with $\mathrm{CO}_{2}$ and water vapor opacities calculated using a correlated-k approach [Liou, 2002], (2) $\mathrm{CO}_{2}$ condensation and sublimation [Haberle et al., 1999], (3) spatially variable thermal inertia and albedo fields based on Viking and Mars Global Surveyor observations (F. Forget, personal communication, 2005), (4) explicit boundary layer treatment [Haberle et al., 1993, 1999], and (5) aerosol transport. Aerosol transport and the atmospheric thermodynamic equations are solved on a $5^{\circ}$ latitude by $6^{\circ}$ longitude Arakawa C grid by the model's dynamical core [Suarez and Takacs, 1995]. The surface topography is based on observations obtained by MOLA [Smith et al., 1999] and the model ceiling is located at the 0.0001 mbar level $(\sim 80 \mathrm{~km})$. In calculating radiative heating rates, the model accounts for solar and thermal infrared absorption/reemission by $\mathrm{CO}_{2}$ and suspended dust. The model includes the effects of diurnally and seasonally varying insolation, as well as the latent heat changes due to the deposition/sublimation of $\mathrm{CO}_{2}$.

\subsection{Dust Cycle}

[10] In this version of the GCM, we prescribe dust opacity values derived from MGS TES spectra during the instrument's first mapping year. These MGS TES $9 \mu \mathrm{m}$ opacity values [Smith, 2004] are temporally averaged over five degree $\mathrm{L}_{\mathrm{s}}$ intervals $\left(\mathrm{L}_{\mathrm{s}}=0-5,5-10\right.$, etc.) at the same horizontal resolution as the GCM. MGS TES provides 12 strips of data 3 pixels wide (giving a spatial resolution per pixel of $\sim 3 \times 9 \mathrm{~km}$ ) every day. These strips roughly run north-south and are spaced $\sim 30^{\circ}$ apart in longitude [Smith 


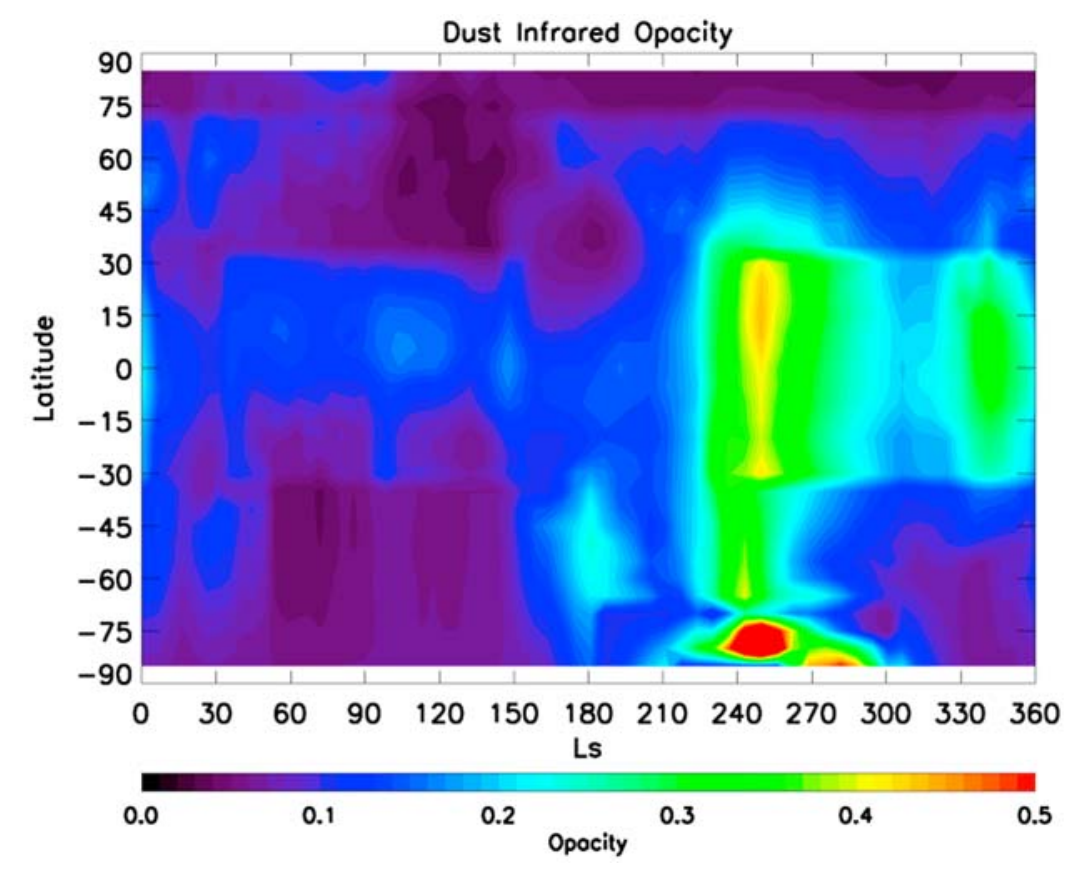

Figure 2. This is a zonal mean of the 72 TES opacity maps ingested into the GCM. Each map is temporally averaged over $5^{\circ}$ of $\mathrm{L}_{\mathrm{s}}$. This is to provide sufficient data sampling within each designated GCM grid box. The maps have spatial resolutions the same as the model ( $5^{\circ}$ latitude $\times 6^{\circ}$ longitude).

et al., 2001b]. We average over five degrees of $\mathrm{L}_{\mathrm{s}}$ in order to obtain sufficient data sampling within each designated GCM grid box (which is $5^{\circ}$ in latitude and $6^{\circ}$ in longitude). As latitudes approach the polar night (where low signal-tonoise prevents reliable data retrieval), an extrapolation function is used to obtain opacities in the polar regions. As the autumn season approaches, this function causes the opacity to temporally decline as an exponential, much like the decay of typical dust storms. For a specific model grid point and $\mathrm{L}_{\mathrm{s}}$, the optical depth (more than twice the $9 \mu \mathrm{m}$ opacity, as determined by Martin [1986] and Clancy et al. [2003]) is determined by interpolating in $\mathrm{L}_{\mathrm{s}}$ space between the two surrounding $\mathrm{L}_{\mathrm{s}}$ map values at a given location. Using Conrath's [1975] prescription with a dependence upon latitude and $\mathrm{L}_{\mathrm{s}}$ (deepest vertical mixing of the dust occurs at the equator at $\mathrm{L}_{\mathrm{s}}=240^{\circ}$; shallowest vertical mixing of dust occurs over the poles at $\mathrm{L}_{\mathrm{s}}=60^{\circ}$ ), the dust's vertical distribution varies spatially and temporally. Figure 2 is a zonal average of the TES opacity maps (as a function of $\mathrm{L}_{\mathrm{s}}$ ) ingested into the model.

[11] Dust is not actively lifted via wind stress or sensible heat flux calculations, but a passive tracer representing dust is injected into the lowest layer of the atmosphere. Dust is lifted at a rate to produce an opacity equivalent to that of the local TES opacity map value. This tracer is radiatively inert and is carried in the model as a means for determining water ice cloud core mass and total number of cloud cores. The dust distribution is allowed to be advected and to undergo sedimentation. If the dust tracer opacity in a column becomes greater than the local TES opacity map value, no lifting occurs until dust sedimentation brings the TES opacity and the dust tracer opacity into sync.

[12] When dust is injected into the model atmosphere, mass $\left(M_{\mathrm{o}}\right)$ and number $\left(N_{\mathrm{o}}\right)$ of dust particles are added to the bottom atmospheric layer according to a log normal distribution for an assigned constant value of $\sigma_{\mathrm{o}}$ (standard deviation of the size distribution) and carried as a mixing ratio. By only carrying mass and number of the dust particles, this is an efficient, and computationally inexpensive, way of describing the aerosol population [Schulz et al., 1998; Rodin, 2002]. Dust particles possess a density of 2500 $\mathrm{kg} / \mathrm{m}^{3}$ and airborne particles are allowed to sediment back to the surface via Stoke's law with the Cunningham slip flow correction [Pruppacher and Klett, 2000].

\subsection{Water Cycle}

[13] A surface water ice source is seasonally exposed at the two most northerly model latitudes (every grid point at $85^{\circ} \mathrm{N}$ and 15 grid points at $80^{\circ} \mathrm{N}$ ) to produce a water ice cap equal in area to that measured [Zuber et al., 1998]. The albedo of the north perennial ice cap at $80^{\circ} \mathrm{N}$ has been increased by $20 \%$ above observed values to reduce sublimation so as to obtain a water cycle comparable to the latest TES values [Smith, 2002, 2004, 2006; Fouchet et al., 2007; M. Smith, private communication, 2007]. Sublimation of water ice off the north polar cap reservoir (or from sites of deposition) is treated the same way that Haberle et al. [1999] do the turbulent exchange of heat, in which the drag and heat coefficients are calculated in a self-consistent way. When sublimation of water ice off the surface occurs, water vapor is added to the lowest atmospheric layer as a mass mixing ratio.

[14] Particle size-dependent aerosols (dust particles, dust cores (i.e., nucleated particles), and cloud particles) are assumed to have a lognormal size distribution with a prescribed species-dependent standard deviation. Given these assumptions the particle size distribution of a given aerosol is fully described by two quantities: the mass and 
number of particles per unit volume (R. M. Haberle et al., The role of the north residual cap in the global Martian water cycle, manuscript in preparation, 2009). These are the quantities transported by the model. In principle, this yields six aerosol related tracers to transport. However, homogeneous nucleation and coagulation are neglected, which means that the number of dust cores is equal to the number of cloud particles, thereby reducing the number of aerosol related tracers to five. The only nonaerosol related tracer the model carries is water vapor. Thus, the model transports a total of six tracers (B. Haberle, private communication, 2009).

[15] Cloud microphysical processes included in the model are nucleation, growth, and sedimentation. The approach taken is based on Montmessin et al. [2002] to which the reader is referred for details. The effect of these processes is calculated after a given transport interval by converting the aerosol mass and number densities back into a lognormal distribution, discretizing that size distribution into bins (nominally 8 bins from 0.1 to 100 microns), and then calculating the effects of nucleation, growth, and sedimentation on the binned size distribution. The updated size distribution is then converted back into a lognormal space, hence mass and number densities, in preparation for the next transport interval (B. Haberle, private communication, 2009).

[16] Water deposition upon the surface occurs via sedimentation of water ice cloud particles through the calculation of the Stokes-Cunningham flow [Pruppacher and Klett, 2000] for a spherical particle. The model also accounts for direct deposition of frost onto the surface from the bottom atmospheric layer. When $5 \mu \mathrm{m}$ of water ice is present on the surface, the albedo is changed to a value of 0.4 from the nominal spatially variable values that were based upon observation and input into the model. Exceptions occur for the north polar ice cap (where the albedo remains the TES-measured value) and at locations where $\mathrm{CO}_{2}$ ground ice occurs $\left(\mathrm{CO}_{2}\right.$ ice albedo takes precedence) .

[17] Water ice cloud particles are radiatively inert for this set of experiments. Even though the clouds remain radiatively inert, we calculate the absorption opacity (for comparison with observation) using

$$
\tau=\frac{3 Q_{a b s} M_{c}}{4 \rho_{c} r_{c}}
$$

where $Q_{a b s}$ is the absorption efficiency of water ice at $12 \mu \mathrm{m}, M_{c}$ is the total mass of the cloud (water ice plus dust nuclei cores) in the atmospheric column $\left(\mathrm{kg} / \mathrm{m}^{2}\right), \rho_{c}$ is the mean cloud particle density, and $r_{c}$ is the area-weighted water ice cloud particle radius in meters [Montmessin et al., 2004].

[18] $Q_{a b s}$ is calculated using an empirically derived formula for water ice particles in the infrared by Yang et al. [2005]:

$$
Q_{a b s}=\frac{\xi_{0}+\xi_{1} D_{e}^{-1}}{1+\xi_{2} D_{e}^{-1}+\xi_{3} D_{e}^{-2}}
$$

where $D_{e}$ is the effective particle size in microns. For a spherical particle, the effective particle size is equal to the maximum dimension of that particle, which is the diameter of the cloud particle. The fitting coefficients are $\xi_{0}=0.855$, $\xi_{1}=81.19, \xi_{2}=73.30$, and $\xi_{3}=87.29$ for a wavelength of $12.2 \mu \mathrm{m}$.

\section{Validating the Aerosol Cycles}

[19] The model in this study is parameterized to simulate a "best fit" (to data) steady state water cycle. The Ames GCMv2.1 requires a spin-up timescale of several years in order for dynamical processes to produce a seasonally varying latitudinal gradient in water vapor abundances. The model is initially started from an isothermal, static state to allow the atmosphere (temperature, pressure, etc.) to adjust to current Martian conditions. Once the water cycle becomes repeatable on a yearly basis within the GCM, the simulation is stopped and the last year analyzed (year 5 in this study). To determine the quality of the simulated water cycle, the water vapor and water cloud content as a function of season are compared to the MGS TES observations [Smith, 2002, 2004, 2006].

\subsection{Water Vapor}

[20] The annual water vapor cycle generated by the model exhibits the seasonality observed by TES [Smith, 2002, 2004, 2006], with a north polar maximum abundance resulting from exposure of the ice deposits at high northern latitudes during northern summer (Figure 3). Maximum atmospheric water vapor abundances in the northern hemisphere are similar in both the model and TES, with values peaking near $60 \mathrm{pr} \mu \mathrm{m}$ over the cap. The maximum atmospheric water vapor abundance during southern summer occurs over the south polar cap and has a value close to $25 \mathrm{pr} \mu \mathrm{m}$ in the model, similar to observation [Smith, 2002]. Enhanced column water vapor abundances progress equatorward as northern summer progresses and the model reproduces the observed northern subtropical winter column water vapor abundance maximum.

\subsection{Water Ice Clouds}

[21] The model produces a water ice cloud cycle that captures the observed spatial and seasonal distribution (Figure 4). An aphelion water ice cloud belt forms between $30^{\circ} \mathrm{N}$ and $15^{\circ} \mathrm{S}$ at an altitude of $\sim 1$ scale height $(\sim 10 \mathrm{~km})$. This cloud belt extends seasonally from $\mathrm{L}_{\mathrm{s}} \sim 30^{\circ}$ to $150^{\circ}$, consistent with the seasonal extent as derived from TES spectra [Smith, 2002, 2004, 2006]. Opacity of the aphelion cloud belt in the model is greater than 0.1 , peaking at 0.12 near $\mathrm{L}_{\mathrm{s}} \sim 90^{\circ}$. This is seasonally consistent with TES observations. However, modeled cloud opacity is about $\sim 20 \%$ less than observed. Polar hood clouds form over the margins of both northern and southern terminators. The southern hemisphere is relatively cloud free during the perihelion season. TES observations show the equatorial cloud belt beginning to reform after $\mathrm{L}_{\mathrm{s}}=270^{\circ}$. From $\mathrm{L}_{\mathrm{s}}=$ $270^{\circ}-360^{\circ}$, these clouds have a peak opacity of $\sim 0.05$. In the model, the equatorial cloud belt begins to reconstitute itself during the same time period, but with peak opacities $\sim 40 \%$ larger. Cloud opacities in the model wane from morning to early afternoon. This cloud activity is supported by Viking orbiter camera data [Tamppari et al., 2003], Viking lander data [Colburn et al., 1989], and the modeled 

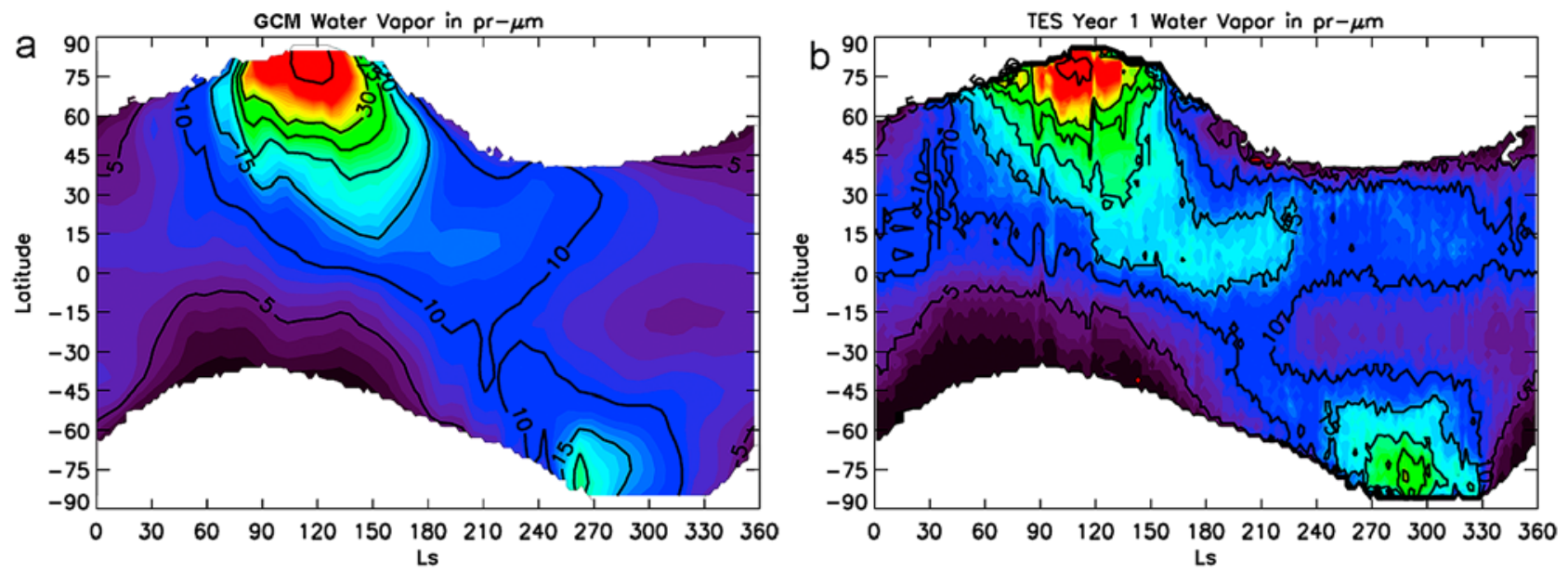

Figure 3. (a) Model-derived zonal mean water vapor abundances in $\mathrm{pr} \mu \mathrm{m}$. (b) TES-derived abundances [Smith, 2004]. Contours are 5, 10, 15, 20, 25, 30, 50, and $70 \mathrm{pr} \mu \mathrm{m}$. The white shading over the poles is where the surface temperatures were too cold for TES to obtain accurate values.

results in the work of Hinson and Wilson [2004]. Similar to the GFDL model results [Hinson and Wilson, 2004], the Ames GCMv2.1 predicts cloud coverage in the predawn hours to be larger in opacity and spatial extent, with the largest opacities occurring over Tharsis. The effective radius of cloud particles is $\sim 4$ microns in the aphelion cloud belt and $<4 \mu \mathrm{m}$ south of the cloud belt, matching observations [Clancy et al., 2003]. The model generates large cloud particle sizes $(\sim 7 \mu \mathrm{m})$ over the north pole during spring and summer, consistent with previous modeling efforts [Colaprete and Toon, 2000; Montmessin et al., 2004].

[22] Possible reasons for the minor differences in cloud conditions between model and observation are many. Hinson and Wilson [2004] note that varying the number of vertical layers in a model changes the overall cloud mass. Atmospheric temperatures over the summer pole are several degrees Kelvin too warm in the model, increasing sublimation and transport of water vapor off the caps. Also, we neglect any radiative effects that clouds might have on their surroundings. The thermodynamic effects of clouds cannot be assumed to be trivial as Hinson and Wilson [2004] have shown that the effects of nighttime clouds on the heating of the surface can be significant. These are all conditions that need to be explored further in future research.

\section{Results}

\subsection{Tropical Distribution of the Simulated Water Ice Deposits}

[23] In order to study the surface spatial distribution of the simulated nighttime tropical water ice deposits, precipitation (snowfall) of water ice in the model is integrated over
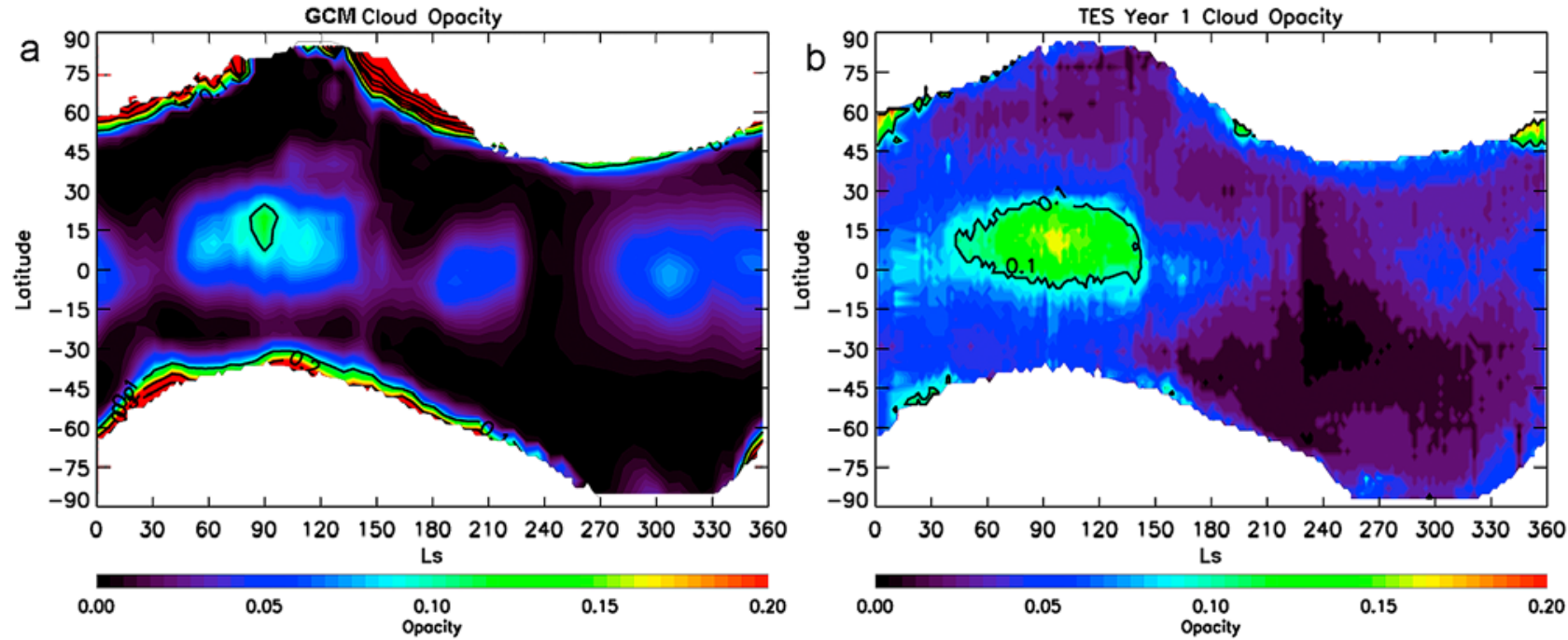

Figure 4. (a) Model-derived zonal mean water ice cloud absorption opacities. (b) TES-derived zonal mean opacities [Smith, 2004]. The model produces an aphelion water ice cloud belt that is consistent both seasonally and spatially with observation. Contours are $0.1,0.2,0.3,0.4,0.5,0.6,0.7$, and 0.8 . The white shading over the poles is where the surface temperatures were too cold for TES to obtain accurate values. 


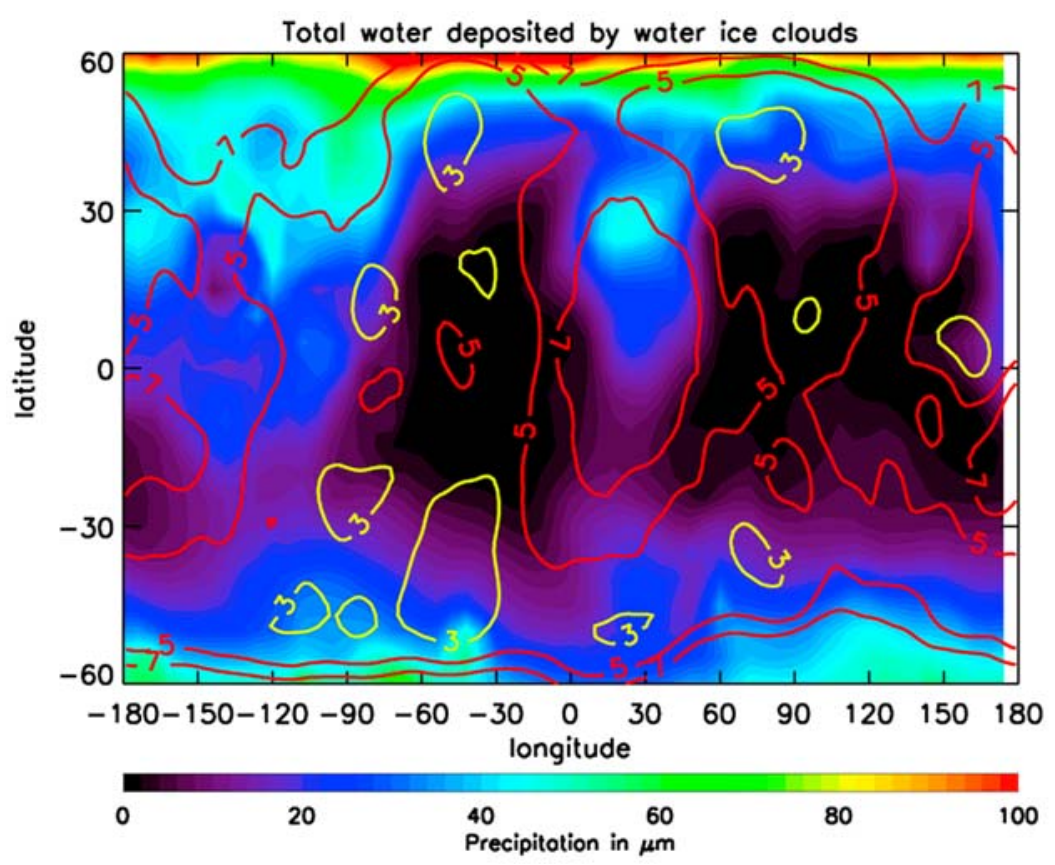

Figure 5. The total simulated annually integrated water ice precipitation from water ice clouds (in $\mu \mathrm{m}$ ) with the $3 \%, 5 \%$, and $7 \%$ by mass observed WEH contours overlain [Feldman et al., 2004a]. Water ice deposits occur in the GCM in a wave number two longitudinal spatial pattern over Arabia and Tharsis [Feldman et al., 2005; Basilevsky et al., 2006].

a full Martian year at each model grid point. The results are plotted in Figure 5 with contours (from Figure 1) overlain representing the tropical WEH-rich regions [Feldman et al., 2004a] to highlight any correlation (or lack thereof). It is important to understand that this result is the total, temporally integrated, water ice precipitated over one Martian year and not total water ice accumulation. As has been mentioned previously, water ice is not thermodynamically stable equatorward of $\sim 45^{\circ}$ [Mellon and Jakosky, 1993].

[24] Water ice precipitation in the model produces relative maxima over Arabia and Tharsis, creating a longitudinal wave number two pattern similar to prior efforts [Hinson and Wilson, 2004; Feldman et al., 2005; Basilevsky et al., 2006]. Relative minima of simulated water ice deposits follow the observed desiccated lanes of Acidalia, Chryse, and Argyre $\left(-45^{\circ} \mathrm{E}\right)$ in the west, and Utopia, Isidis, and Hellas $\left(+90^{\circ} \mathrm{E}\right)$ in the east. While the model results correlate with the observed longitudinal placement of the equatorial WEH-rich regions on Mars [Feldman et al., 2005], the simulated maximum in the longitude corridor of Arabia is skewed northward and the derived maximum near Medusae Fossae $\left(\sim 180^{\circ} \mathrm{E}, 15^{\circ} \mathrm{S}\right)$ is either absent in the simulation or shifted significantly northward in comparison to the WEH maxima.

[25] Figure 6 is a breakdown of the total simulated water ice deposited upon the surface (precipitation + direct deposition) integrated over each of the four seasons (spring, summer, fall, and winter). Deposits are relatively uniform across the equator during northern spring. Water ice deposits are substantially greater in the northern hemisphere tropics than in its southern counterpart throughout northern summer. During northern fall and winter, only the northern hemisphere experiences water ice deposits in the tropics [Feldman et al., 2005]. Deposits in the north during this time are facilitated by the descending branch of the Hadley cell driving water vapor transported from the southern hemisphere down toward the cooling nighttime surface. In the south, warmer temperatures due to perihelion do not allow nighttime near-surface temperatures to cool below the local dew point.

\subsection{Mechanism for Precipitation}

[26] Precipitation, or "snow," falling to the surface in the model occurs at night through the formation of a ground fog. Daytime temperatures are sufficiently warm to keep the near-surface atmospheric layer unsaturated. Daytime relative humidity is often 0.1 or less, even in locations of preferred deposition. At night, as temperatures cool, water vapor condenses out over Tharsis and Arabia (Figure 7a), with the relative humidity being unity, of course. In the desiccated regions, however, relative humidity can be less than 0.5 . In the morning, at sunrise, the deposited water ice quickly sublimes leaving frost-free ground. These simulated nighttime clouds over Tharsis and Arabia are consistent with the nighttime clouds simulated in the work of Wilson et al. [2007]. The contour lines in Figure 7 indicate the surface topography (in kilometers) at model resolution. The ground fog often forms over locations of steeply sloping topography.

[27] Except for times near the equinoxes (when for a brief period two Hadley cells circulate, one each from the equator toward each pole) [Haberle and Jakosky, 1990; Smith et al., 2001b; Read and Lewis, 2004], the daytime equatorial nearsurface winds are from the fall/winter to the spring/summer hemisphere. At night, near-surface winds decouple from the larger-scale Hadley circulation. Near-surface air cools radiatively and also through being in conductive contact with the cold ground, and this cold dense air descends down the 

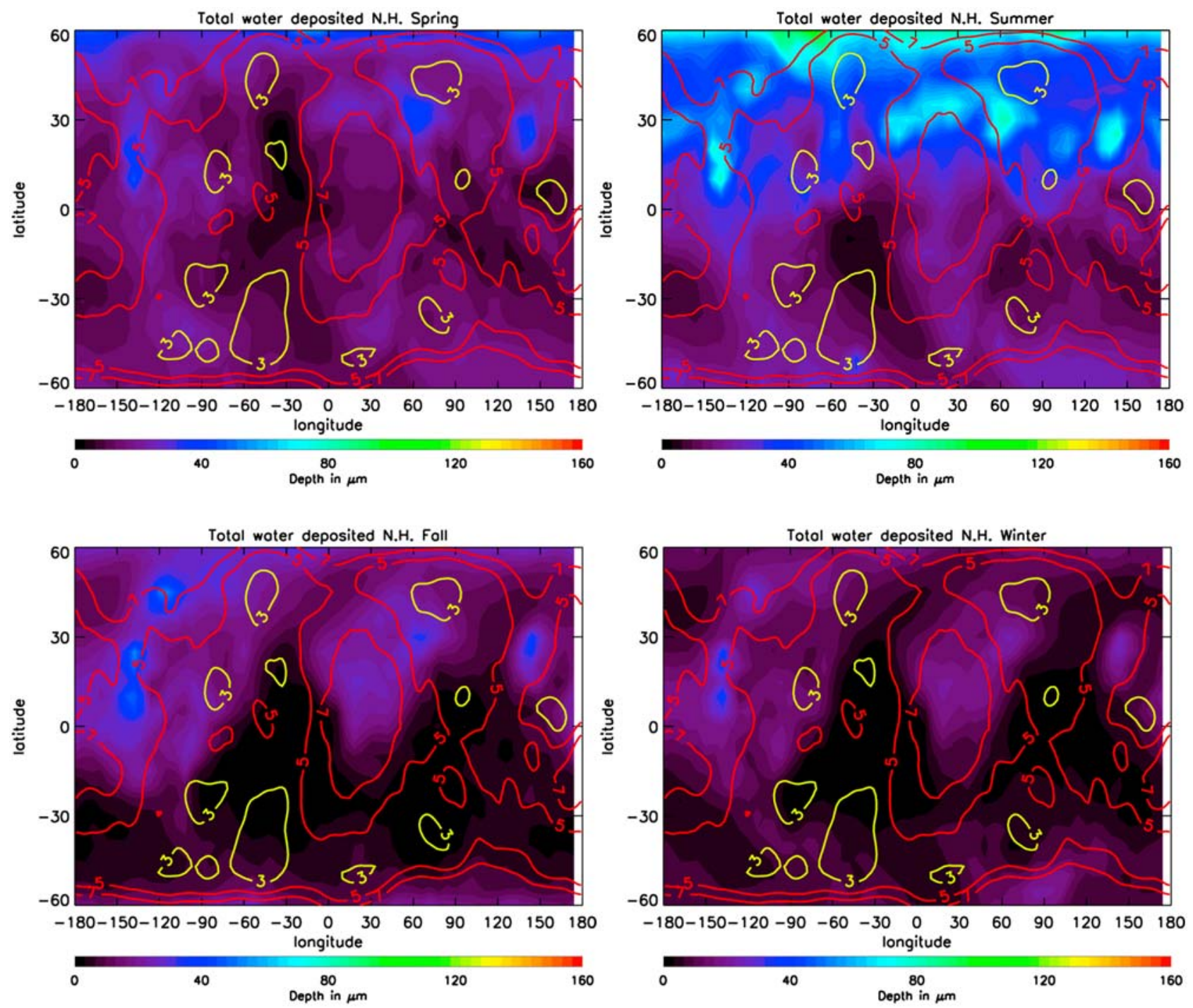

Figure 6. These plots represent the total integrated water ice deposited (precipitation and direct deposition) by season in the model. The contour lines represent 3\%, 5\%, and 7\% by mass observed WEH [Feldman et al., 2004a].

slope of the local topography (Figure 7b). At locations where the temperature is below the condensation temperature (which depends on the relative humidity), cloud formation and precipitation occur. The coldest near-surface, nighttime temperatures occur at the locations of lowest thermal inertia (Figure 7c). These conditions coincide with the locations of Tharsis and Arabia [Feldman et al., 2005], thus a wave number two longitudinal pattern of water ice deposits occurs.

[28] The effects of topography cannot be underestimated. Besides the effect of katabatic winds explained above, Hinson and Wilson [2004] explains further the importance of topography in facilitating water ice precipitation in the regions of Tharsis and Arabia. MGS radio occultation measurements obtained during late northern summer $\left(\mathrm{L}_{\mathrm{s}}=\right.$ $\left.134^{\circ}-162^{\circ}\right)$ exhibit nighttime midaltitude $(0.3-2$ mbars $)$ temperature inversions which are largest and most frequent above elevated terrain such as that at Tharsis and Arabia. Using the GFDL GCM, Hinson and Wilson [2004] provides evidence for thermal tides being the trigger for these temperature inversions. These temperature inversions occur at longitudes of enhanced tidal amplitude, which corresponds to the longitudinal corridors over Tharsis and Arabia. A prominent cloud layer forms near the temperature minimum beneath the inversion. Ground fogs often form at the surface underneath these inversions since this elevated terrain often has low thermal inertia, hence cooler nighttime surface temperatures [Hinson and Wilson, 2004]. The cloud layer steadily descends throughout the night, merging with, and enhancing the ground fog below [Hinson and Wilson, 2004], which increases the nighttime precipitation upon the surface at these locations. We see similar temperature inversions over elevated terrain in the Ames GCM. However, the inversions are less than half $(\sim 3 \mathrm{~K})$ that seen by Hinson and Wilson [2004], and the corresponding cloud layer does not descend throughout the night toward the surface. It is possible that the lack of radiatively active clouds in the Ames GCM may contribute to the discrepancy between the two models and needs to be further 
examined in future research, as this could lead to increased precipitation.

\subsection{Nighttime Cloud Structure}

[29] The nighttime precipitation arises as a result of the formation of the ground fog. Figure 8 shows cloud ice thickness in parts per million (ppm; mass-to-mass) water ice
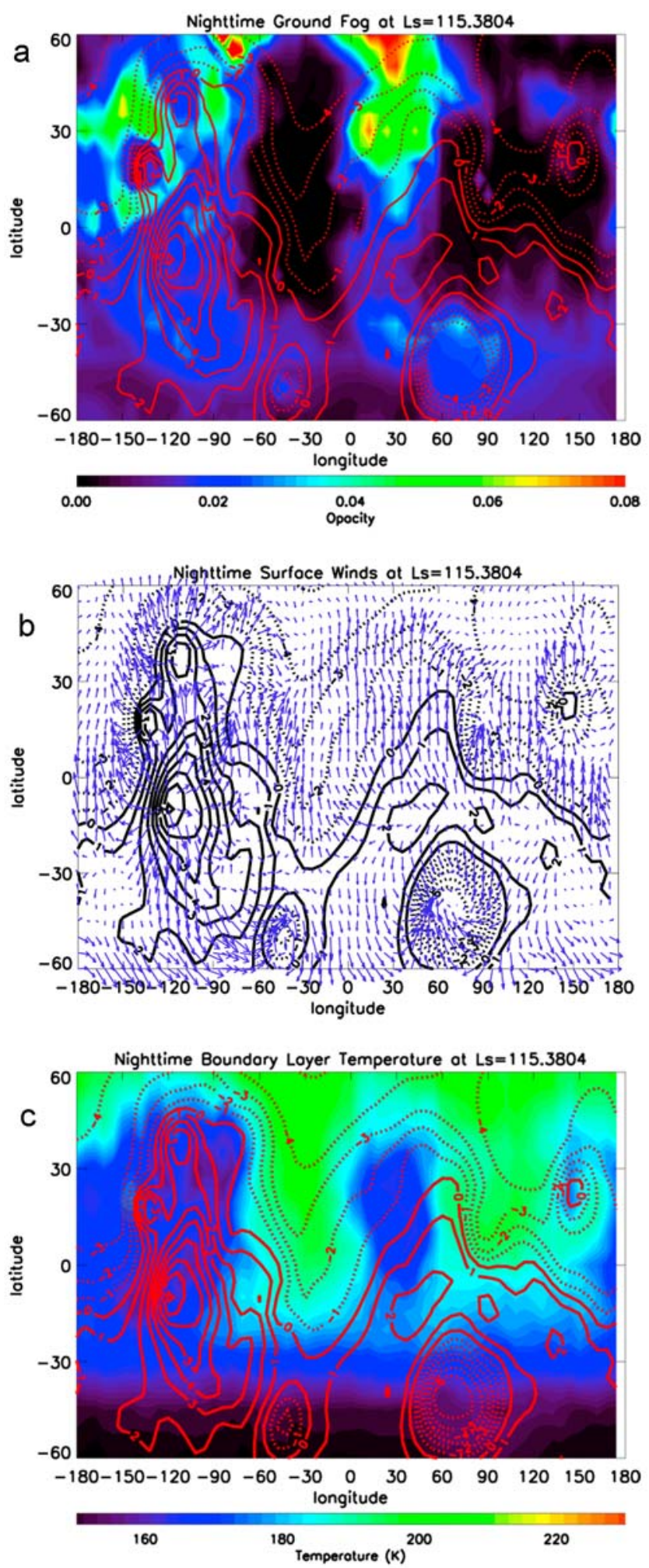

as a function of height (pressure in mbars) above the surface. These meridional slices show the clear distinction between the ground fog and the aphelion season cloud deck at $\sim 10 \mathrm{~km}(1-2$ mbar pressure level) above the surface. Hinson and Wilson [2004] predict similar ground fog formations, but no mention of the precipitation effects is made. These simulated ground fogs match the detected nighttime ground fogs by MOLA in the locale of $18^{\circ}-$ $25^{\circ} \mathrm{S}$ in late northern summer $\left(\mathrm{L}_{\mathrm{s}}=136^{\circ}\right.$ and $\left.151^{\circ}\right)$ [Neumann et al., 2003]. The ground fog extends from the ground to $\sim 200 \mathrm{~m}$ above the surface. The cloud deck, however, is contained inside the 1-2 mbar pressure level. This is consistent with observations by Clancy et al. [1996]. This is the aphelion season and the tropical "aphelion" cloud belt is prominent during this time (refer to Figure 4), both in the model and in the observations.

[30] Ground fog formation is not directly dependent upon the development of the aphelion season cloud deck. Figure 8 contains two meridional slices, one through the very foggy longitude at $18^{\circ} \mathrm{E}$, and the other through the fog deficient longitude of $-30^{\circ} \mathrm{E}$ (refer to Figure 7). At both meridians, the aphelion clouds are prominent at the 1-2 mbar height, with peak abundances reaching $\sim 35 \mathrm{ppm}$. At $18^{\circ} \mathrm{E}$, a dense ground fog is present throughout the tropical region equatorward of $30^{\circ}$ latitude (located between the white arrows on Figure 8a), while there is no ground fog in this region at $-30^{\circ} \mathrm{E}$. To emphasize that ground fog formation is not directly dependent upon the development of the aphelion season cloud deck, in Figure 8, the most substantial fog occurs north (poleward of $30^{\circ} \mathrm{N}$ ) of Arabia $\left(18^{\circ} \mathrm{E}\right)$, where the aphelion clouds are not present.

\subsection{Wet Regions Versus Desiccated Regions}

[31] Figure 9 is a vertical profile of the temperature and water vapor abundance mixing ratio from locations of preferred deposition and desiccation in the model. Both locations are on the equator, with the deposition region being in Arabia $\left(18^{\circ} \mathrm{E}\right)$ and the desiccation region in Chryse $\left(-30^{\circ} \mathrm{E}\right)$. These locations correspond to the same longitudes focused upon in Figure 8. Arabia is a region of preferred

Figure 7. (a) The nighttime (0000-0600 LT mean) nearsurface ground fog water ice opacity. The red contour lines represent the underlying topography in $\mathrm{km}$. The season is northern summer $\left(\mathrm{L}_{\mathrm{s}} \sim 115^{\circ}\right)$. The cloud opacity is solely that contributed by the ground fog. This opacity is calculated only from the surface to a height of $\sim 200 \mathrm{~m}$ since this is the vertical extent of the ground fog. (b) The direction and relative magnitude of nighttime (00000600 LT mean) surface winds during the same season $\left(\mathrm{L}_{\mathrm{s}}\right.$ $\sim 115^{\circ}$ ) as the nighttime surface fog. Black contours are surface topography in $\mathrm{km}$. At night, near-surface circulation decouples from the global thermally direct (Hadley) circulation and flows down the slope of the topography. (c) The simulated nighttime (0000-0600 LT mean) atmospheric temperatures in the lowest atmospheric layer for the same season $\left(\mathrm{L}_{\mathrm{s}} \sim 115^{\circ}\right)$ as Figures $7 \mathrm{a}$ and $7 \mathrm{~b}$. The red contours are surface topography in $\mathrm{km}$. Local minima occur over Arabia $\left(10^{\circ} \mathrm{N}, 20^{\circ} \mathrm{E}\right)$, Tharsis $\left(15^{\circ} \mathrm{S},-100^{\circ} \mathrm{E}\right)$, and Elysium Mons $\left(20^{\circ} \mathrm{N}, 140^{\circ} \mathrm{E}\right)$ regions of maximum water ice deposition. 

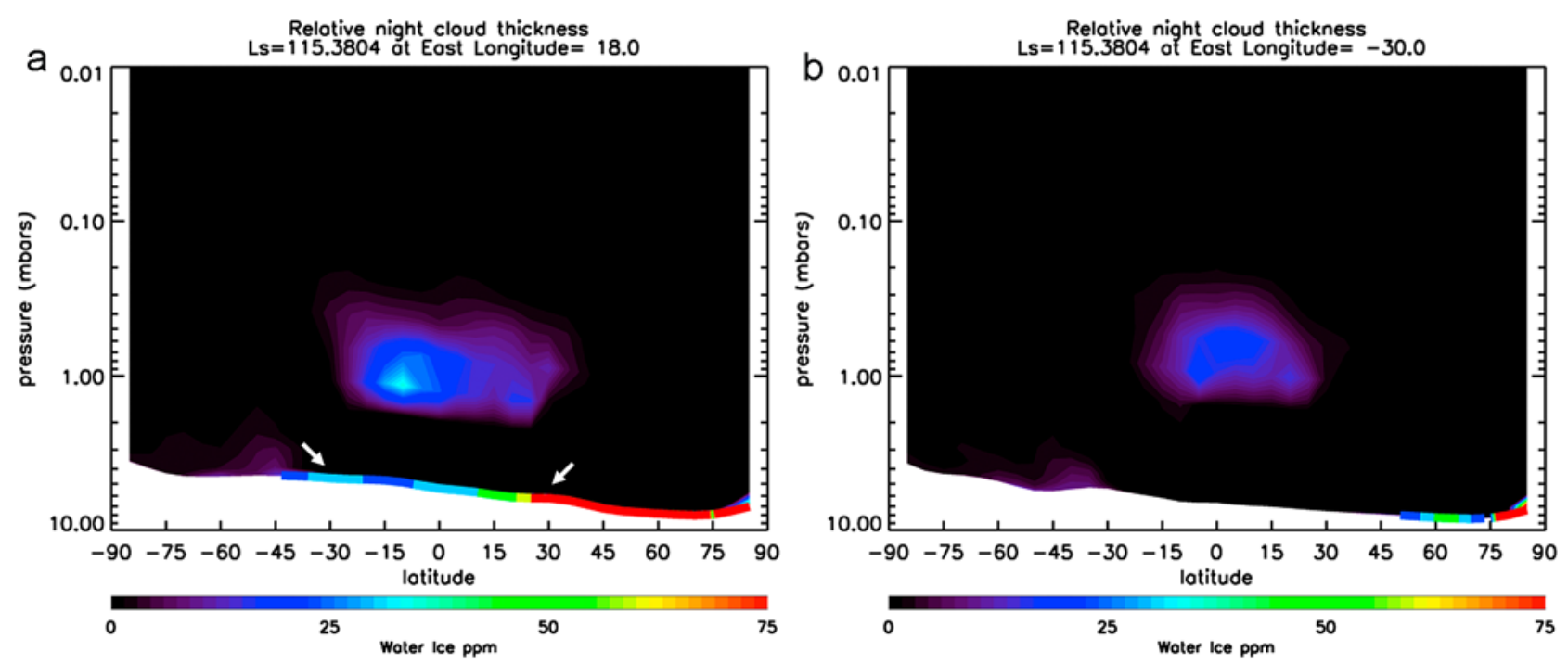

Figure 8. (a) The simulated vertical structure of the water ice clouds in parts per million at night $(0000-$ $0600 \mathrm{LT}$ mean) for $18^{\circ} \mathrm{E}$, a longitude of preferred deposition. (b) Same as Figure 8a, except for $-30^{\circ} \mathrm{E}$, a desiccated longitude. The thick-colored line near the surface is fog and not ice deposits upon the surface. The arrows on the left point to the formation of a tropical ground fog at $18^{\circ} \mathrm{E}$ longitude. The right shows no such tropical ground fog formation. The white shading is the surface.

deposition relative to Chryse because the nighttime, nearsurface atmospheric temperature is $20 \mathrm{~K}$ cooler and contains threefold more water vapor (increased vapor content leads to greater deposition depths when saturation temperature is obtained). In fact, the nighttime temperatures in the regions of preferred deposition are routinely $\sim 20 \mathrm{~K}$ cooler [Kreslavsky et al., 2008] than those in the desiccated regions on a year-round basis. This condition leads to preferential precipitation in Arabia (and Tharsis) over the desiccated regions.

\section{Discussion}

\subsection{WEH in Arabia and Medusae Fossae}

[32] The debate on the origin of the equatorial WEH-rich regions on Mars may not be settled until in situ measurements are made, confirming the state of the WEH in these locations. However, the results of this paper allow for a discussion concerning the current atmosphere's role in the formation or retention of the observed equatorial WEH-rich regions. Based on the northern hemisphere bias in the water ice deposition, it is not likely that current atmospheric conditions alone formed (or maintain) the equatorial WEH-rich regions in Arabia or Medusae Fossae.

[33] The WEH signature observed in Arabia is latitudinally symmetric about the equator and centered longitudinally at $\sim 15^{\circ} \mathrm{E}$. Current Martian obliquity has remained at $25^{\circ} \pm 2^{\circ}$ for the past $\sim 200,000$ years [Laskar et al., 2004]. During this time, a number of GCM predictions place the dust growth in Arabia to be near $\pm 1 \mu \mathrm{m}$ a year [Basu et al., 2004; Newman et al., 2005; Kahre et al., 2006; Nelli, 2006], a change of only $\pm 10-20 \mathrm{~cm}$ over this time span. Thus, any minerals hydrated by the atmosphere during the current epoch should still be detectable by the NS due to the limited mobility of dust in Arabia during this current epoch. However, since the WEH signature in Arabia is symmetric about the equator, and the nighttime water ice deposits in this region are not, the present-day water ice deposition is unlikely to have played a dominant role in the formation/ maintenance of the equatorial WEH-rich regions. We have neglected the role of water vapor diffusion into the regolith in this paper. To first order, one can argue that the inclusion of such an effect would not change the conclusion. The locations of greatest water vapor content coincide both in the model (Figure 9) and in observations [Smith, 2002] with the locations of greatest water ice deposition in the model. Thus, the regions with the greatest diffusive rates into the

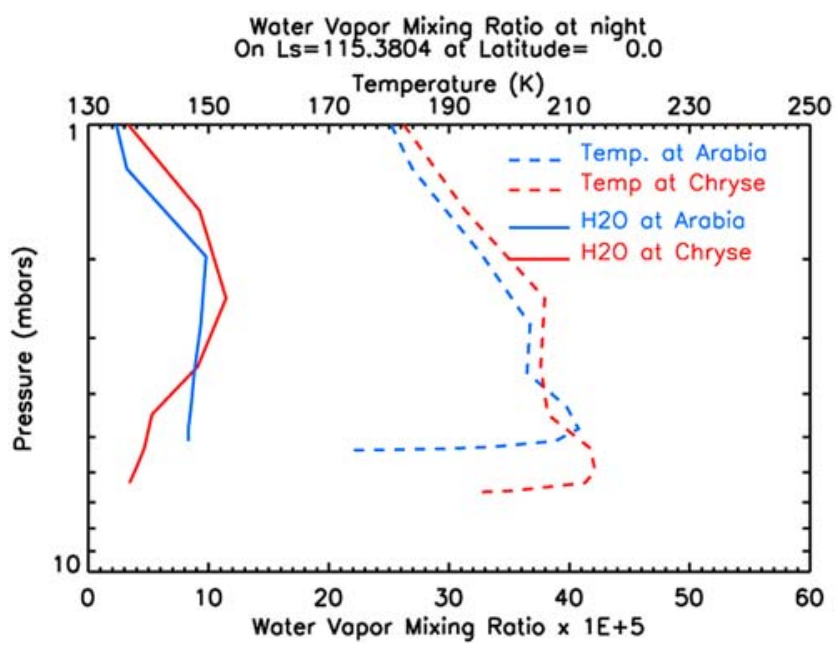

Figure 9. Simulated nighttime (0000-0600 LT mean) vertical water vapor mixing ratio and temperature profile for a location of preferred deposition (Arabia; $0^{\circ} \mathrm{N}, 18^{\circ} \mathrm{E}$ ) and desiccation $\left(\right.$ Chryse; $\left.0^{\circ} \mathrm{N},-30^{\circ} \mathrm{E}\right)$. The offset in pressure is due to a $2 \mathrm{~km}$ change in elevation between the two locations. Arabia is $20 \mathrm{~K}$ colder and is threefold wetter, making condensation more likely than in Chryse. 
regolith (and greatest subsurface water ice gain) would correlate with the regions of maximum water ice deposition.

[34] Medusae Fossae in the southern hemisphere contains the other large tropical abundance of WEH, with a maximum of $\sim 10 \%$ by mass. Model results suggest water ice deposition is northern hemisphere biased (globally), and especially lacking in Medusae Fossae. A local minimum of water ice deposition and precipitation is predicted in this region under current climate conditions. Like the Arabian WEH feature, it is unlikely that current water ice deposition could have produced/maintained the observed WEH signature on its own.

[35] One aspect ignored in this discussion is the effect of precession on the Martian climate. While the obliquity of Mars has not varied greatly over the past $\sim 200,000$ years, precession has changed the argument of perihelion numerous times in that time frame [Laskar et al., 2004]. Results by Montmessin et al. [2007] produce significant water vapor transport to the southern hemisphere during a time of reversed perihelion. They note that the southern hemisphere experiences higher abundances of water vapor than today at all seasons, while northern water vapor abundances are only increased during spring and summer. A southern lowlatitude cloud belt forms during southern summer, which limits the water vapor transported northward. The formation of a southern hemisphere summer cloud belt traps moisture in the southern hemisphere by not allowing water vapor to ascend to the cross-equatorial flow of the Hadley cell. By raising the water vapor content in the southern hemisphere as a whole, nighttime water ice deposition may be enhanced in the southern hemisphere compared to the northern hemisphere. Thus, it is possible that the equatorial WEHrich regions may be a product of nighttime water ice deposition over the period of a full precession cycle. This possibility needs to be thoroughly studied in the future.

\subsection{Summary}

[36] Since the discovery of a relatively large tropical source of WEH [Feldman et al., 2002; Boynton et al., 2002; Mitrofanov et al., 2002; Feldman et al., 2004a], effort has been given to prescribe its origin through correlations with surface features and/or atmospheric phenomena [Jakosky et al., 2005; Feldman et al., 2005]. One of the better correlations born from these ideas was the connection between tropical WEH and nighttime tropical water ice deposits simulated in the Ames GCM [Feldman et al., 2005]. Simulated current atmospheric conditions on Mars produce a zonal wave number two longitudinal pattern of nighttime water ice deposits in the tropics. The WEHdesiccated regions [Feldman et al., 2005] along the longitudinal corridors $-45^{\circ} \mathrm{E}$ and $+90^{\circ} \mathrm{E}$ correlate well with the simulated regions showing no water ice deposits. Regions of preferred nighttime water ice deposits, Arabia and Tharsis, occur at locations of low-surface thermal inertia within the same longitudinal corridors as the tropical WEH. These deposits occur at night via the formation of a ground fog that descends down the local slope of the topography and through direct deposition of frost upon the surface. The low thermal inertia leads to nighttime conditions over Tharsis and Arabia that are up to $\sim 20 \mathrm{~K}$ cooler throughout the year [Kreslavsky et al., 2008] than in the surrounding areas of lesser deposition $\left(-45^{\circ} \mathrm{E}\right.$ and $\left.+90^{\circ} \mathrm{E}\right)$. Water ice deposited over the Tharsis and Arabia regions contain a bias favoring the northern hemisphere. This bias makes it likely that the current water ice deposition did not play a critical role in the formation of the equatorially symmetric WEHrich region of Arabia or the southern tropical WEH region of Medusae Fossae.

[37] Acknowledgments. Special thanks to Melinda Kahre and Jeff Hollingsworth for their valuable insight concerning the GCM tracer physics. We would also like to thank Ruslan Kuzmin, whose helpful discussions benefited this paper greatly. Support for this work was provided by NASA Planetary Atmospheres Programs (NAG5-12123), LANL IGPP/ Space Phy-1611-06, New Mexico Space grant, and MDAP-NNG04GJ94G.

\section{References}

Basilevsky, A. T., et al. (2006), Search for causes of the low epithermal neutron flux anomaly in the Arabia Terra Region (Mars), Sol. Syst. Res., 40, 355-374, doi:10.1134/S0038094606050017

Basu, S., M. I. Richardson, and R. J. Wilson (2004), Simulation of the Martian dust cycle with the GFDL Mars GCM, J. Geophys. Res., 109, E11006, doi:10.1029/2004JE002243.

Bibring, J.-P., et al. (2005), Mars surface diversity as revealed by the OMEGA/Mars Express observations, Science, 307, 1576-1581, doi:10.1126/science. 1108806 .

Boynton, W. V., et al. (2002), Distribution of hydrogen in the near-surface of Mars: Evidence for subsurface ice deposits, Science, 297, 81-85, doi:10.1126/science. 1073722 .

Boynton, W. V., et al. (2004), The Mars Odyssey Gamma-Ray Spectrometer instrument suite, Space Sci. Rev., 110, 37-83, doi:10.1023/ B:SPAC.0000021007.76126.15.

Byrne, S., and A. Ingersoll (2003), A sublimation model for Martian south polar ice features, Science, 299, 1051-1053, doi:10.1126/science. 1080148.

Clancy, R. T., et al. (1996), Water vapor saturation at low altitudes around mars aphelion: A key to Mars climate?, Icarus, 122, 36-62, doi:10.1006/ icar. 1996.0108

Clancy, R. T., M. J. Wolff, and P. R. Christensen (2003), Mars aerosol studies with the MGS TES emission phase function observations: Optical depths, particle sizes, and ice cloud types versus latitude and solar longitude, J. Geophys. Res., 108(E9), 5098, doi:10.1029/2003JE002058.

Colaprete, A., and O. B. Toon (2000), The radiative effects of Martian water ice clouds on the local atmospheric temperature profile, Icarus, 145, 524-532, doi:10.1006/icar.2000.6364.

Colburn, D. J., J. B. Pollack, and R. Haberle (1989), Diurnal variations in optical depth at Mars, Icarus, 79, 159-189, doi:10.1016/0019. 1035(89)90114-0.

Conrath, B. J. (1975), Thermal structure of the Martian atmosphere during the dissipation of the dust storms of 1971, Icarus, 24, 36-46, doi:10.1016/0019-1035(75)90156-6.

Davies, D. W., C. B. Farmer, and D. D. Laporte (1977), Behavior of volatiles in Mars' polar areas: A model incorporating new experimental data, J. Geophys. Res., 82, 3815-3822, doi:10.1029/JB082i026p03815.

Farmer, C. B., and P. F. Doms (1979), Global seasonal variation of water vapor on Mars and the implications of permafrost, J. Geophys. Res., 84, 2881-2888, doi:10.1029/JB084iB06p02881.

Feldman, W. C., et al. (2002), Global distribution of neutrons from Mars: Results from Mars Odyssey, Science, 297, 75-78, doi:10.1126/ science. 1073541 .

Feldman, W. C., et al. (2004a), Global distribution of near-surface hydrogen on Mars, J. Geophys. Res., 109, E09006, doi:10.1029/2003JE002160.

Feldman, W. C., et al. (2004b), Hydrated states of $\mathrm{MgSO}_{4}$ at equatorial latitudes on Mars, Geophys. Res. Lett., 31, L16702, doi:10.1029/ 2004GL020181.

Feldman, W. C., et al. (2005), Topographic control of hydrogen deposits at low latitudes to midlatitudes of Mars, J. Geophys. Res., 110, E11009, doi:10.1029/2005JE002452.

Fialips, C. I., J. W. Carey, D. T. Vaniman, W. C. Feldman, and M. T. Mellon (2005), Hydration state of zeolites, clays, and hydrated salts under present-day Martian surface conditions: Can hydrous minerals account for Mars Odyssey observations of near-equatorial water-equivalent hydrogen?, Icarus, 178, 74-83, doi:10.1016/j.icarus.2005.04.020.

Fouchet, T., et al. (2007), Martian water vapor: Mars Express PFS/LW observations, Icarus, 190, 32-49, doi:10.1016/j.icarus.2007.03.003.

Haberle, R., and B. Jakosky (1990), Sublimation and transport of water from the north residual polar cap on Mars, J. Geophys. Res., 95, 14231437, doi:10.1029/JB095iB02p01423. 
Haberle, R. M., H. C. Houben, R. Hertenstein, and T. Herdtle (1993), A boundary-layer model for Mars: Comparison with Viking Lander and entry data, J. Atmos. Sci., 50, 1544-1559, doi:10.1175/15200469(1993)050<1544:ABLMFM>2.0.CO;2.

Haberle, R. M., M. M. Joshi, J. R. Murphy, J. R. Barnes, J. T. Schofield, G. Wilson, M. Lopez-Valverde, J. L. Hollingsworth, A. F. C. Bridger, and J. Schaeffer (1999), General circulation model simulations of the Mars Pathfinder atmospheric structure investigation/meteorology data J. Geophys. Res., 104, 8957-8974, doi:10.1029/1998JE900040.

Hinson, D. P., and R. J. Wilson (2004), Temperature inversions, therma tides, and water ice clouds in the Martian tropics, J. Geophys. Res., 109, E01002, doi:10.1029/2003JE002129.

Jakosky, B., and R. Haberle (1992), The seasonal behavior of water on Mars, in Mars, edited by H. H. Kieffer et al., pp. 969-1016, Univ. of Ariz. Press, Tucson.

Jakosky, B. M., M. T. Mellon, E. S. Varnes, W. C. Feldman, W. V. Boynton, and R. M. Haberle (2005), Mars low-latitude neutron distribution: Possible remnant near-surface water ice and a mechanism for its recen emplacement, Icarus, 175, 58-67, doi:10.1016/j.icarus.2004.11.014

Kahre, M. A., J. R. Murphy, and R. M. Haberle (2006), Modeling the Martian dust cycle and surface dust reservoirs with the NASA Ames General Circulation Model, J. Geophys. Res., 111, E06008, doi:10.1029/2005JE002588.

Kreslavsky, M. A., J. W. Head, and D. R. Marchant (2008), Periods of active permafrost layer formation during the geological history of Mars: Implications for circum-polar and mid-latitude surface processes, Planet Space Sci., 56, 289-302, doi:10.1016/j.pss.2006.02.010.

Laskar, J., A. C. M. Correia, M. Gastineau, F. Joutel, B. Levrard, and P. Robutel (2004), Long term evolution and chaotic diffusion of the insolation quantities of Mars, Icarus, 170, 343-364, doi:10.1016/ j.icarus.2004.04.005.

Leighton, R. B., and B. C. Murray (1966), Behavior of carbon dioxide and other volatiles on Mars, Science, 153, 136-144, doi:10.1126/ science.153.3732.136

Liou, K. N. (2002), An Introduction to Atmospheric Radiation, Int. Geophys. Ser, vol. 84, Academic, San Diego, Calif.

Martin, T. Z. (1986), Thermal infrared opacity of the Mars atmosphere, Icarus, 66, 2-21, doi:10.1016/0019-1035(86)90003-5.

Mellon, M. T., and B. M. Jakosky (1993), Geographic variations in the thermal and diffusive stability of ground ice on Mars, J. Geophys. Res., 98, 3345-3364, doi:10.1029/92JE02355.

Mitrofanov, I., et al. (2002), Maps of subsurface hydrogen from the high energy neutron detector, Mars Odyssey, Science, 297, 78-81, doi:10.1126/science.1073616.

Montmessin, F., P. Rannou, and M. Cabane (2002), New insights into Martian dust distribution and water ice cloud microphysics, J. Geophys. Res., 107(E6), 5037, doi:10.1029/2001JE001520.

Montmessin, F., F. Forget, P. Rannou, M. Cabane, and R. M. Haberle (2004), Origin and role of water ice clouds in the Maritan water cycle as inferred from a general circulation model, J. Geophys. Res., 109, E10004, doi:10.1029/2004JE002284.

Montmessin, F., R. M. Haberle, F. Forget, Y. Langevin, R. T. Clancy, and J.-P. Bibring (2007), On the origin of perennial water ice at the south pole of Mars: A precession-controlled mechanism?, J. Geophys. Res., 112 E08S17, doi:10.1029/2007JE002902.

Nelli, S. M. (2006), Numerical modeling study of Martian aerosols: Noncondensable gases, dust, and water in the Martian atmosphere, Ph.D. dissertation, N. M. State Univ., Las Cruces.

Neumann, G. A., D. E. Smith, and M. T. Zuber (2003), Two Mars years of clouds detected by the Mars Orbiter Laser Altimeter, J. Geophys. Res., 108(E4), 5023, doi:10.1029/2002JE001849.

Newman, C. E., S. R. Lewis, and P. L. Read (2005), The atmospheric circulation and dust activity in different orbital epochs on Mars, Icarus, 174, 135-160, doi:10.1016/j.icarus.2004.10.023.

Pruppacher, H. R., and J. D. Klett (2000), Microphysics of Clouds and Precipitation, 416 pp., Springer, New York.
Read, P. L., and S. R. Lewis (2004), The Martian Climate Revisited: Atmosphere and Environment of a Desert Planet, Praxis Publ., Chichester, U. K.

Rodin, A. V. (2002), On the moment method for the modeling of cloud microphysics in rarefied turbulent atmospheres: I. Condensation and mixing, Sol. Syst. Res., 36, 97-106, doi:10.1023/A:1015266131539.

Schorghofer, N., and O. Aharonson (2005), Stability and exchange of subsurface ice on Mars, J. Geophys. Res., 110, E05003, doi:10.1029/ 2004JE002350.

Schulz, M., Y. J. Balkanski, W. Guelle, and F. Dulac (1998), Role of aerosol size distribution and source location in a three-dimensional simulation of a Saharan dust episode tested against satellite-derived optical thickness, J. Geophys. Res., 103, 10,579-10,592, doi:10.1029/97JD02779.

Smith, D. E., et al. (1999), The global topography of Mars and implications for surface evolution, Science, 284, 1495-1503, doi:10.1126 science. 284.5419 .1495 .

Smith, M. D. (2002), Annual cycle of water vapor on Mars as observed by the Thermal Emission Spectrometer, J. Geophys. Res., 107(E11), 5115, doi:10.1029/2001JE001522.

Smith, M. D. (2004), Interannual variability in TES atmospheric observations of Mars during 1999-2003, Icarus, 167, 148-165, doi:10.1016/ j.icarus.2003.09.010

Smith, M. D. (2006), TES atmospheric temperature, aerosol optical depth, and water vapor observations 1999-2004, paper presented at second workshop on Mars atmosphere modeling and observation, Cent. Natl. d'Etud. Spatiales, Granada, Spain.

Smith, M. D., J. C. Pearl, B. J. Conrath, and P. R. Christensen (2001a), One Martian year of atmospheric observations by the Thermal Emission Spectrometer, Geophys. Res. Lett., 28, 4263-4266, doi:10.1029/ 2001GL013608.

Smith, M. D., J. C. Pearl, B. J. Conrath, and P. R. Christensen (2001b), Thermal Emission Spectrometer results: Mars atmospheric thermal structure and aerosol distribution, J. Geophys. Res., 106, 23,929-23,945, doi:10.1029/2000JE001321.

Smith, M. D., M. J. Wolff, R. T. Clancy, and S. L. Murchie (2009), Compact Reconnaissance Imaging Spectrometer observations of water vapor and carbon monoxide, J. Geophys. Res., 114, E00D03, doi:10.1029/ 2008JE003288

Suarez, M. J., and L. L. Takacs (1995), Technical report series on global modeling and data assimilation. volume 5: Documentation of the AIRES/ GEOS dynamical core, version 2, NASA Tech. Memo. 104606.

Tamppari, L. K., R. W. Zurek, and D. A. Paige (2003), Viking-era diurnal water-ice clouds, J. Geophys. Res., 108(E7), 5073, doi:10.1029/ 2002JE001911.

Wilson, R. J., G. A. Neumann, and M. D. Smith (2007), Diurnal variation and radiative influence of Martian water ice clouds, Geophys. Res. Lett., 34, L02710, doi:10.1029/2006GL027976.

Yang, P., H. Wei, H.-L. Huang, B. A. Baum, Y. X. Hu, G. W. Kattawar, M. I. Mishchenko, and Q. Fu (2005), Scattering and absorption property database for nonspherical ice particles in the near- through farinfrared spectral region, Appl. Opt., 44, 5512-5523, doi:10.1364/ AO 44.005512

Zuber, M. T., et al. (1998), Observations of the north polar region of Mars from the Mars Observer Laser Altimeter, Science, 282, 2053-2060 doi:10.1126/science.282.5396.2053.

W. C. Feldman, Planetary Science Institute, Tucson, AZ 85719-2395, USA. (Feldman@psi.edu)

J. R. Murphy, Department of Astronomy, New Mexico State University, Las Cruces, NM 88003, USA. (murphy@nmsu.edu)

S. M. Nelli, Department of Atmospheric, Oceanic, and Space Sciences, University of Michigan, Ann Arbor, MI 48109, USA. (snelli@umich.edu) J. R. Schaeffer, NASA Ames Research Center, Mail Stop 245-3, Moffett Field, CA 94035-1000, USA. (James.R.Schaeffer@nasa.gov) 